nowhere can I find a discussion of why the Gogo fossils are so exceptionally well preserved. Nodular preservation of fishes is common in the Devonian, but the specimens are usually nowhere near as perfect as these. Any future second edition of the book should certainly be expanded to include a chapter on this topic. But in the end these are the minor blemishes of a delightful book.

My first ever contribution to Nature, 18 years ago, was a News \& Views piece on John Long's Gogo fish research (Nature 337, 511-512, 1989). I ended it by saying that the scientific value of the Gogo fossils is incalculable, This remains just as true today, and Swimming in Stone is a worthy testament to the fact. Per E. Ahlberg is in the Department of Physiology and Developmental Biology, Uppsala University, Norbyvägen 18A, 75236 Uppsala, Sweden.

\title{
An ode to symmetry
}

\section{Why Beauty Is Truth: The History of Symmetry \\ by lan Stewart \\ Basic Books: 2007.304 pp. \$26.95}

\section{Joseph Mazur}

Had Keats lived long enough to read Ian Stewart's latest book, Why Beauty is Truth, he might have been inspired to write a sixth great ode, soft-piping sweet melodies in praise of symmetry. But what did Keats mean in Ode on a Grecian Urn when he wrote some of the most famous lines in English poetry: "Beauty is truth, truth beauty - that is all/ Ye know on earth, and all ye need to know"?

Stewart is onto something deep, something mathematicians must have been keenly aware of since Greeks began turning urns. What is the underlying beauty of mathematics? Is it the artful way a proof is expressed? Or is it something deeper - something guiding pythagorean and platonist mathematicians to see better, something at the molecular structure of mathematics, some "unravish'd bride of quietness", some "Attic shape" — that enlightens and delights us.

Stewart, a professor of mathematics at the University of Warwick, is renowned for his popular science books, but Why Beauty is Truth is without a doubt his finest. If it were just an authentic history of mathematics, it would be creditable. If it were only for its lively informal style, its historical characters, its intrigue ("The Galois group has a terrible secret"), its beautiful prose, it would be praiseworthy. Yet, its real uniqueness - its power - is in what it uncovers. It brings us the heart of why mathematicians pursue mathematics.

Beauty is not always as visible as the iridescent butterfly on the cover of Stewart's book. We are aware that it is not the dazzling colour that makes such an insect beautiful, but rather its shape, in particular its symmetry. It is this kind of beauty that Stewart's book reveals. We encounter it most obviously when we perceive it in geometry, in the wings of a butterfly, the sections of a cone, or the appearance of regular solids. But Stewart wants us to 'see' the invisible symmetries of algebra.

He starts with Évariste Galois, a young nineteenth-century French revolutionary who saw them when he discovered - ostensibly on the night before he died in a duel - how symmetry could be used to decide which polynomial equations could be solved by radicals and which could not. This is where the story of symmetry really takes off, with a pedantic question about solutions to equations. And it is where we are first told that symmetry is a process rather than a shape; it is a way to rearrange things. Symmetry then takes on a rigorous definition to become more than just a pleasing pattern. It had been an aesthetic part of geometry since Pythagoras, but Stewart tells us that Galois' revelation inspired others, starting with Sophus Lie's realization that geometric invariants associated with symmetry groups could determine the existence of solutions to differential equations. From this step forward, Lie groups and their associated Lie algebras emerge and invade. Symmetry then becomes deeply rooted in almost every area of mathematics, relativity and quantum physics, from the use of special and unitary orthogonal groups to the transformations of space-time and the gauge symmetries of Maxwell's equations, which led to the standard model of the theory of all fundamental particles.

How does Stewart do it? How can he make such phenomenally difficult material so easy to understand without giving sophisticated readers a sense that he is oversimplifying, and at the same time create something that is such a joy to read? He uses tangible things as examples, describing the fundamental forces of nature by throwing dishes on a kitchen floor. Towards the end he gives us a warning, as if apologizing for pedantry. "Bear with me," he says, "and don't worry too much about the odd piece of unexplained jargon. Sometimes we just need a convenient word to keep track of the main players." And with that, we stiffen, expecting the worst, but he goes on as before, escorting us through the deep forestal connections between mathematics and physics, guiding us with his inimitable clarity. But apart from some terms clear only to professionals, there's nothing to bear - we understand it.

When we come to Einstein, Stewart says: "Acres of print...have been devoted to Einstein's life and work." Yet when he tells us about Einstein's life and work, he makes us feel as if we've never heard it before. We may not fully understand the geometry of Minkowski space-time, the non-euclidean metrics or the bizarre consequences of relativity, but we come to believe we partly understand them - the ultimate aim of popular science narratives.

Why Beauty is Truth is a brilliant interweaving of politics, history and intrigue, with characters living ordinary lives, described in the spirit of a Russian novel.

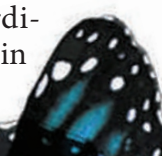

